\title{
Management of penile fracture
}

\section{Jesse Ory, MD; Greg Bailly, MD, FRCSC}

Department of Urology, Dahousie University, Halifax NS, Canada

Cite as: Can Urol Assoc J 2019;13(6Supp14):S72-4. http://dx.doi.org/10.5489/cuai.5932

\section{Case}

A 40-year old male presented to the emergency department (ED) with penile swelling, bruising, and pain. He reported that while he was having vaginal intercourse with his female partner in the "missionary position," his penis buckled. He reported slowly losing tumescence and that he felt minimal discomfort initially. He denied hearing the classical "snap," which can be associated with a penile fracture. He noticed the rapid development of bruising and swelling of his penile shaft. He did not attempt any further sexual activity that night. The following day, despite the bruising and swelling, he was able to achieve an erection adequate for intercourse but there was too much pain to continue. At this point, he presented to the ED, approximately 36 hours after the original injury. He denied any hematuria or blood per urethra.

On physical exam, the patient had extensive bruising along the shaft of the penis, including the skin superior to the suspensory ligament, as well as scrotal edema and ecchymosis (Fig. 1). There was no palpable granuloma or defect along the penile shaft. Since he presented late, with a somewhat atypical presentation, magnetic resonance imaging (MRI) was performed to evaluate for possible penile fracture (Fig. 2).

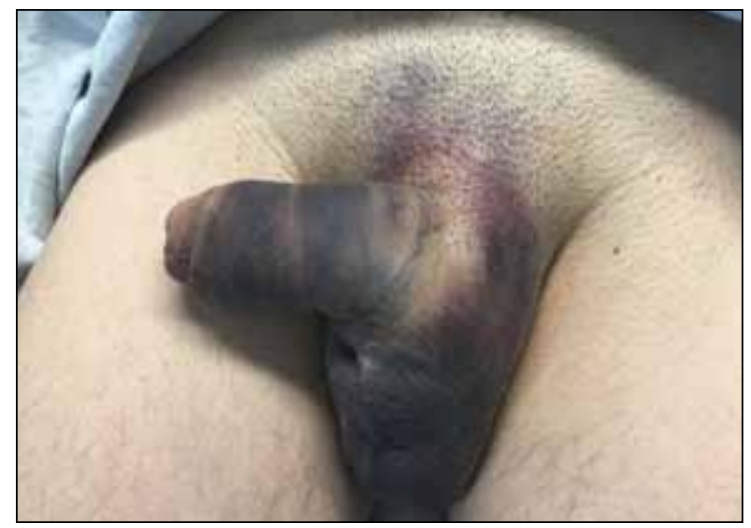

Fig. 1. Visual inspection of patient on presentation in the emergency department.

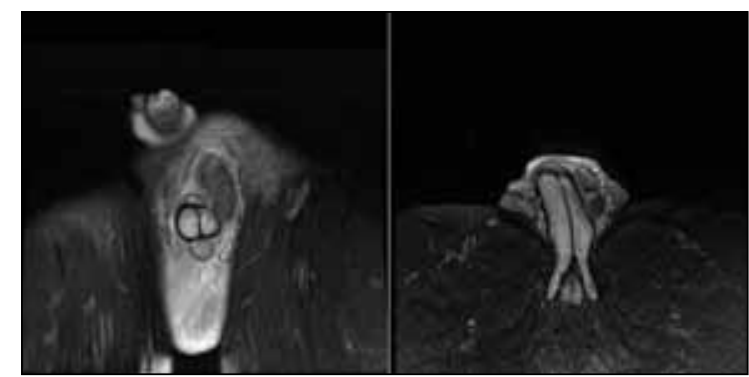

Fig. 2. 1.5T magnetic resonance imaging of the penis showing a 5 $\mathrm{mm}$ defect on the left side of the tunica albuginea with overlying hematoma.

\section{Introduction}

The most common form of penile trauma is penile fracture, which results in rupture of the cavernosal tunica albuginea. Up to $77 \%$ of cases occur during consensual intercourse and most commonly occur in the rear entry ("doggy style") position. ${ }^{1,2}$ It can occur during any position, most commonly associated when the erect penis comes out of the vagina and does not go back in properly, buckling as the pelvis moves forward. Alternative causes include masturbation, rolling over in bed, and "taqandaan," a Middle Eastern practice involving the forcible bending of the penis to cause 
detumescence. In some Middle Eastern trials, taqandaan was responsible for the majority of penile fractures. ${ }^{3}$

\section{Clinical presentation}

Penile fracture typically presents after the man and/or his partner hear a sudden "snapping" or "popping" noise followed by pain and rapid detumescence. Swelling of the shaft develops quickly, with spreading ecchymosis occurring in most patients. ${ }^{4}$ Bruising can extend to the scrotum and lower abdomen if Buck's fascia is violated. A urethral injury occurs in $21 \%$ of patients and must be considered when evaluating patients with penile fracture, especially those presenting with hematuria, blood per urethra, or retention..$^{5,6}$

\section{Diagnosis}

Diagnosis and decision to operate is typically done on a clinical basis. ${ }^{7,8}$ In equivocal cases, imaging adjuncts can aid in diagnosis and localization of the defect. Ultrasonography (US) may help visualize the location of the tunical rupture but may not be reliable to help rule out the diagnosis. One series noted a sensitivity of US of only $50 \%$, while another found that US failed to detect a tunical rupture in $22 \%$ of cases. ${ }^{8,9}$

Magnetic resonance imaging (MRI) plays an important role in confirming the diagnosis, and supporting evidence for MRI has increased in recent years. One mapping trial of 25 patients showed a detection rate of US and a 1.5T MRI at $88 \%$ and $100 \%$, respectively. ${ }^{10}$ Two other trials, with 15 and 30 patients, respectively, reported $100 \%$ sensitivity of 1.5T MRI to detect penile fracture. ${ }^{11,12}$

\section{Management}

Recent evidence for timing of operative repair reinforces the importance of immediate and early surgical repair. If a clinical presentation strongly suggests penile fracture, surgical exploration should occur as soon as possible. Delaying surgical exploration should only be considered if the diagnosis is questionable and imaging can be arranged quickly. The British Association of Urologic Surgeons recommends repair within 24 hours. ${ }^{13}$ One trial showed that early surgery $(<24$ hours) resulted in a complication rate of $7.6 \% \mathrm{com}-$ pared to $68.7 \%$ with later surgery ( 24 hours to four days). ${ }^{14}$ Additionally, a multicentre trial with 137 patients showed worse erectile function if the time from emergency room admission to surgical intervention was greater than 8.23 hours. ${ }^{15}$ Finally, a systematic review of 12 trials favoured immediate. $(<24$ hours) repair over delayed ( $>24$ hours) repair, but only for improving curvature. ${ }^{16}$

The initial approach to surgery includes a circumcising, degloving penile incision or a longitudinal incision over the expected area of the defect. At our centre, we prefer a cir- cumferential incision if the patient has had a circumcision. Often, flexible cystoscopy can take place at the beginning of the case if necessary, and the subsequent choice of incision can be made if urethral repair is necessary. The most common location for tunical disruption in penile fracture is ventrolateral, where the tunica is thinnest. ${ }^{17}$ When a urethral injury is present, the most common type of lesion is a bilateral corporal injury. ${ }^{6}$ Closure of the defect in the tunica albuginea should be performed with absorbable suture, such as polyglactin $910\left(\mathrm{Vicryl}^{\circledR}\right) .^{13}$

Early operative repair is a key principle of management, as conservative management or delayed surgery can lead to missed urethral injury and stricture or fistula, penile abscess, curvature, persistent hematoma, and impotence. Postoperative complications are reported in $4-12 \%$, with a $1-5 \%$ rate of erectile dysfunction. ${ }^{17-19}$ Patients undergoing conservative management are at higher risk for complications, with rates upwards of $80 \%$ in some trials. ${ }^{20,21}$ Postoperative care suggestions include avoiding sexual intercourse for six weeks; ${ }^{13,22}$ sexual activity can be resumed when pain, swelling, and bruising has revolved.

\section{The American Urological Association (AUA) and European Association of Urology (EAU) guidelines}

The AUA guidelines highlight that penile swelling and ecchymosis are the most common symptoms of penile fracture, with rapid detumescence and a snapping or popping sound experienced by most. Prompt surgical exploration and repair in patients with signs or symptoms of penile fracture is recommended. Equivocal cases can be investigated by MRI or US. At the time of repair, the AUA guidelines state that the urethra must be evaluated if there is concomitant hematuria, blood at the meatus, or urinary retention. Retrograde urethrogram (RUG) or cystoscopy are acceptable options. To repair the corporal defect, a circumcising or midline incision may be used, and absorbable suture should be used to close the tunica. Finally, it is recommended to initiate some form of counselling if impairment in sexual or reproductive function is anticipated as a result of the injury. ${ }^{23}$

The EAU guidelines differ slightly from the AUA on several topics. The EAU recommends performing a urinalysis on any patient with genital trauma, and any amount of micro- or macrohematuria should prompt a RUG. It acknowledges that in the case of penile fracture, a cystoscopy at the time of repair is more often employed by most urologists. In addition to MRI and US, cavernosography can be considered in patients with a suspected penile fracture when the clinical presentation is equivocal. The EAU guidelines also highlight that simple penile hematomas, which are not usually associated with abrupt detumescence, are usually easily distinguishable and can be treated with non-steroidal anti-inflammatory drugs and 


\section{Case followup}

In the case presented above, the patient's MRI showed an obvious tunical rupture of approximately $5 \mathrm{~mm}$ in diameter on the proximal, lateral position (5 o'clock) of the left corporal body. Cystoscopy showed a normal urethra. The patient was not circumcised and a vertical incision was made over the expected area of rupture. Hematoma was evacuated and the tunical defect was identified and closed with a 3-0 polyglactin suture in a running fashion. Dartos fascia was closed with polyglactin suture and skin was closed with 3-0 chromic suture.

The patient was kept overnight and discharged the following day. His pain was much improved. He unfortunately returned nine days postoperatively with a penile abscess that required drainage and antibiotics. He was seen in follow up at two months and was reporting healthy, painless erections with no signs of curvature.

ice. Following repair, the EAU reports a rate of impotence of only $1.3 \%$, with conservative management highly discouraged, as impotence rates can be as high as $62 \%{ }^{24}$

Competing interests: Dr. Bailly has participated in advisory board meetings, been a speaker for, received honoraria from, and participated in clinical trials supported by Allergan, Astellas, and Pfizer. Dr. Ory reports no competing personal or financial conflicts.

This paper has been peer reviewed.

\section{References}

1. Barros R, Schulze L, Ornellas AA, et al. Relationship between sexual position and severity of penile fracture. Int J Impot Res 2017;29:207. https://doi.org/10.1038/iiir.2017.24

2. Haas CA, Brown SL, Spirnak JP. Penile fracture and testicular rupture. World I Urol 1999;17:101-6. https://doi.org/10.1007/s003450050114

3. Zargooshi J. Penile fracture in Kermanshah, Iran: The long-term results of surgical treatment. BJU Int 2002;89:890-4. https://doi.org/10.1046/j.1464-410X.2002.02745.x
4. Muentener $M$, Suter $S$, Hauri $D$, et al. Long-term experience with surgical and conservative treatment of penile fracture. J Urol 2004;172:576-9. https://doi.org/10.1097/01.ju.0000131594.99785.1c

5. Pariser JJ, Pearce SM, Patel SG, et al. National patterns of urethral evaluation and risk factors for urethral injury in patients with penile fracture. Urology 2015;86:181-5. htrps://doi.org/10.1016/i. urology.2015.03.039

6. Barros $R$, Silva MIS, Antonucci $V$, et al. Primary urethral reconstruction results in penile fracture. Ann $R$ Coll Surg Engl 2018;100:21-5. https://doi.org/10.1308/rsann.2017.0098

7. Zargooshi J. Sexual function and tunica albuginea wound healing following penile fracture: An 18-year followup study of 352 patients from Kermanshah, Iran. J Sex Med 2009;6:1141-50. https://doi.org/10.1111/i.1743-6109.2008.01117.x

8. Mahapatra RS, Kundu AK, Pal DK. Penile fracture: Our experience in a tertiary care hospital. World J Mens Health 2015;33:95. htrps://doi.org/10.5534/wimh.2015.33.2.95

9. Agarwal MM, Singh SK, Sharma DK, et al. Fracture of the penis: A radiological or clinical diagnosis? A case series and literature review. Can J Urol 2009;16:4568-75.

10. Zare Mehriardi M, Darabi $M$, Bagheri $S M$, et al. The role of ultrasound (US) and magnetic resonance imaging (MRI) in penile fracture mapping for modified surgical repair. Int Urol Nephrol 2017;49:937-45. https://doi.org/10.1007/s11255-017-1550-x

11. Guler I, Odev K, Kalkan $\mathrm{H}$, et al. The value of magnetic resonance imaging in the diagnosis of penile fracture. Int Braz I Urol 2015;41:325-8. https://doi.org/10.1590/S1677-5538.IBJU.2015.02.20

12. Saglam $E$, Tarhan $F$, Hamarat $M B$, et al. Efficacy of magnetic resonance imaging for diagnosis of penile fracture: A controlled study. Investig Clin Urol 2017;58:255. https://doi.org/10.4111/icu.2017.58.4.255

13. Rees RW, Brown G, Dorkin T, et al. British Association of Urological Surgeons (BAUS) consensus document for the management of male genital emergencies — penile fracture. BJU Int 2018;122:26-8. https://doi.org/10.1111/bju.14167

14. Naouar $S$, Boussaffa $H$, Braiek $S$, et al. Management of penile fracture: Can it wait? African I Urol 2018;24:56-9. htrps://doi.org/10.1016/i.afiu.2017.07.006

15. Bozzini $G$, Albersen $M, O t e r o ~ J R$, et al. Delaying surgical treatment of penile fracture results in poor functional outcomes: Results from a large retrospective multicentre European study. Eur Urol Focus 2018;4:106-10. https://doi.org/10.1016/i.euf.2016.02.012

16. Wong NC, Dason S, Bansal RK, et al. Can it wait? A systematic review of immediate vs. delayed surgical repair of penile fractures. Can Urol Assoc J 2017;11:53-60. https://doi.org/10.5489/cuai.4032

17. De Luca $F$, Garaffa $G$, Falcone $M$, et al. Functional outcomes following immediate repair of penile fracture: A tertiary referral centre experience with 76 consecutive patients. Scand J Urol 2017;51:170-5. https://doi.org/10.1080/21681805.2017.1280532

18. El-Bahnasawy MS, Gomha M. Penile fractures: The successful outcome of immediate surgical intervention. Int J Impot Res 2000;12:272-7. https://doi.org/10.1038/si.jiji.3900571

19. Ghanem AN. Penile fracture in Kermanshah, Iran: The long-term results of surgical treatment. BJU Int 2003;91:301-2. https://doi.org/10.1046/j.1464-410X.2003.t01-1-04066.x

20. Yapanoglu $T$, Aksoy $Y$, Adanur $S$, et. al. Seventeen years' experience of penile fracture: Conservative vs. surgical treatment. J Sex Med 2009;6:2058-63. https://doi.org/10.1111/i.1743-6109.2009.01296.x

21. Özorak A, Hoşcan MB, Oksay T, et al. Management and outcomes of penile fracture: 10 years' experience from a tertiary care centre. Int Urol Nephrol 2014;46:519-22. https://doi.org/10.1007/s11255013-0531-y

22. Vilson F, Macdonald S, Terlecki R. Contemporary management of penile fracture: A urologist's guide. Curr Sex Heal Reports 2016;8:91-6. hittps://doi.org/10.1007/s1 1930-016-0069-y

23. Morey AF, Brandes S, Dugi DD, et al. Urotrauma: AUA guideline. J Urol 2014;192:327-35. https://doi.org/10.1016/i.juro.2014.05.004

24. Summerton DJ, Diakovic N, Kitrey ND, et al. EAU guidelines on urological trauma. Eur Urol 2013. Available at: http://www.uroweb.org/gls/pdf/23. Accessed Feb. 18, 2019.

Correspondence: Dr. Greg Bailly, Department of Urology, Dalhousie University, Halifax NS, Canada; gbailly@dal.ca 